\title{
Can citizen pressure influence politicians' communication about climate change? Results from a field experiment
}

\author{
Seth Wynes ${ }^{1,2}$ D J John Kotcher ${ }^{3} \cdot$ Simon D. Donner ${ }^{1}$
}

Received: 3 November 2020 / Accepted: 28 August 2021/ Published online: 16 September 2021

(C) The Author(s), under exclusive licence to Springer Nature B.V. 2021

\begin{abstract}
Urgent reductions in greenhouse gas emissions depend on governments implementing and enforcing rigorous climate policy. Individuals in democracies seeking to persuade government officials to reduce greenhouse gas emissions can take steps such as voting, protesting, and contacting officials directly, but it is unclear how effective each of these actions is in changing the behavior of elected officials. Here we take advantage of the public nature of social media to evaluate the actual efficacy of climate campaign emails using an original, real-world experiment where 335 Members of Canadian Parliament were asked by constituents to post a pro-climate message to their Twitter account. Only one Member of Parliament posted the exact text suggested by the campaign. After scraping and coding 18,776 tweets, we first find no evidence that a public health messaging frame is more effective than a standard environmental frame in eliciting proclimate posts. Furthermore, we find only a marginally significant relationship between volume of constituent contact and increased pro-climate tweeting from Members of Parliament. Follow-up interviews with political staffers suggest that analog alternatives may be more effective than campaign emails in some cases. Interview findings also reveal that some offices receive low levels of constituent communication on climate change, indicating that increased pressure from constituents could still be consequential.
\end{abstract}

Keywords Climate advocacy $\cdot$ Social media $\cdot$ Climate politics $\cdot$ Political participation

Seth Wynes

swynes@alumni.ubc.ca

1 The Department of Geography, University of British Columbia, Vancouver, BC, Canada

2 Department of Geography, Planning \& Environment, Concordia University, Montreal, QC, Canada

3 Center for Climate Change Communication, George Mason University, Fairfax, VA, USA 


\section{Introduction}

The combined emissions targets of national governments are insufficient to avoid dangerous levels of planetary warming as defined by the Paris Climate Agreement (Rogelj et al. 2016). Partially in response to this lack of ambition, over one million people around the world attended protests in March of 2019 with the intent of pressuring government officials into greater action on climate change (Wahlström et al. 2019). Despite increasing political mobilization, when asked to describe what they see as the most effective way for individuals to reduce greenhouse gas emissions, a recent study found that members of the public favor consumer actions like reducing personal vehicle usage over political actions like voting (Wynes et al. 2020). Interestingly, political advocacy is often a necessary condition for enabling consumer action, since structural barriers may prevent widespread consumer change (Ockwell et al. 2009). And while consumers can seek out a broad literature on the most effective steps they can take to reduce greenhouse gas emissions (Gardner and Stern 2008; Lacroix 2018; Wynes and Nicholas 2017), beyond some evidence that voting is a high-impact climate action (Wynes et al. 2021), there is little research to inform the decisions of an individual hoping to use political action to mitigate climate change (Han and Barnett-Loro 2018).

It is difficult to compare the effectiveness of different political actions and different consumer actions, but it may at least be possible to create a hierarchy whereby an individual could identify the political actions that are most meaningful at effecting change. A survey of the European Members of Parliament, for instance, suggested that politicians viewed voting as highly effective, writing letters or emails to elected officials as moderately effective, and online discussions as less effective ways to influence political decision-making (Hooghe and Marien 2012). But these approximate rankings may not hold in other jurisdictions or remain consistent across multiple issues. A sudden influx of constituent communications on a new issue, for example, might cause greater response from officials than the same volume of communication on an issue that officials are already addressing.

A degree of dissonance between the policies being enacted by officials and the opinions expressed by constituents can be explained by the "spiral of silence" on climate change. Since climate mitigation measures only become effective when a sufficient number of actors participate, governments and individuals who perceive a large proportion of their peers as unmotivated may be less willing to take on the individualized costs associated with climate action (Mildenberger and Tingley 2017a). According to this theory on the role of "secondary beliefs" (beliefs about what others believe), climate action is then at least partially reliant on individuals signaling that they are willing to act on climate and other individuals correctly interpreting those signals.

Unfortunately, individuals not only underestimate public concern for climate change in other nations (Taddicken et al. 2019), they also tend to underestimate concern for climate change among their own peers, causing them to self-silence (Geiger and Swim 2016). Furthermore, both citizens and political elites underestimate public support for carbon regulation (Hertel-Fernandez et al. 2019; Mildenberger and Tingley 2017b), which depresses support for further action. Additional research in the USA has found that the misperceptions of political elites may be partly driven by disproportionate contact from Republican constituents, who are more likely to be opposed to climate action (Broockman and Skovron 2018). Such misperceptions have also proven difficult to correct, as officials are unwilling to revise their estimates of constituent preference even in the face of strong public polling data (Kalla and Porter 2019). In the UK, research suggests that silence from constituents on climate 
change discourages Members of Parliament from acting on climate change, since they do not believe that doing so would be representing the needs of their electorate (Willis 2018). As there is broad evidence that citizen concern for climate change is partially driven by cues from elites (Brulle et al. 2012; Carmichael and Brulle 2017; Merkley and Stecula 2020; Rinscheid et al. 2020), there is value in either group jumpstarting a feedback loop where increased expressions of concern by elites or the public amplify concern and action in the other group.

Many environmental activists currently rely on online campaigns through social media and email to recruit members of the public to pressure elected officials. Prior to widespread use of digital communication, legislators could discern which messages came from constituents based on their address or the area code of their phone number, but emails and social media communications largely mask the location of the sender. Emails and social media have also lowered the cost of communication, such that issues which constituents are not very passionate about can still generate a high volume of online correspondence (Cluverius 2017). Thus, a large volume of communication no longer signals salience, and legislators may rely less on these signals to inform their choices (Cluverius 2017; McDonald 2019).

The presence of dishonest communication strategies may exacerbate the lack of trust displayed by legislators. Astroturfing, the act of falsely imitating grassroots organizing (McNutt and Boland 2007), includes dishonest mass communication campaigns from interest groups. Interest groups might make use of members' contact information without their permission or contact legislators who are not in the same jurisdiction as the members. Legislators who become aware of such tactics may then devalue future communications with similar characteristics, even if they are sent by constituents in good faith.

Given indicators of change in the way that legislators interpret signals from their constituents, it is important for grassroots organizations and concerned citizens to know how their outreach is now received. Past research has demonstrated the variable ways in which officials react to correspondence from their constituents. A study in the USA made use of emails from fictitious citizens to show that politicians are less responsive to minorities (Butler and Broockman 2011), and an experiment featuring letters from actual individuals found that politicians are more responsive to service requests than to policy requests (Butler et al. 2012). In the UK, elected officials provided higher quality responses to information rich letters than to information poor letters from citizen interest groups (Richardson and John 2012). The results of this research suggest that even within a single type of action, such as writing a letter, changes to authorship or format can alter the effectiveness of that political action.

The Canadian political system offers an interesting case to examine mass communication campaigns on climate change. Support for climate change policies is higher in Canada than in the USA, with broad (though heterogenous) support for carbon pricing across the nation (Mildenberger et al. 2016). Canada is a parliamentary democracy; the national House of Commons is composed of 338 Members of Parliament (MPs), each representing constituents residing in their electoral district (or riding). The four major federal parties have varying levels of ambition on climate policies and targets, with only a fringe party formed in 2018 openly denying the existence of human-caused climate change. In the months leading up to the most recent federal election, climate change became a priority issue for Canadian voters (Bricker 2019). Still, it is not clear that Canadian politicians have come to terms with this shift in preference of the electorate. Canadian climate policies are projected to fall short of Canada's own target set out in its Nationally Determined Contribution to the Paris Agreement, for instance (Environment and Climate Change Canada 2020). 
An ideal experiment to evaluate the efficacy of a political campaign would be to test whether members of a legislature who receive a greater volume of constituent correspondence are more likely to vote or write new motions in line with stated constituent preferences. However, legislative voting usually conforms to party lines (Nokken 2000). In Canada, for example, even a successful campaign might only sway one or two MP votes out of 338 and therefore go undetected by statistical tests. Surveys of legislators can instead be used to elicit the legislator's opinions on what they believe is effective in changing their political decisions (Cluverius 2017; Hooghe and Marien 2012), but results from these investigations may be subject to social desirability bias (Nederhof 1985). For instance, a legislator may feel compelled to incorrectly report that they value constituent preference above party mandate in order to conform to public expectations. Survey techniques such as asking a participant for the perceived opinions of their peers and randomized response or list experiment can be used to reduce social desirability bias, though they have limitations (Glynn 2013). Additionally, surveys of elected officials often feature low response rates (Docherty 2001; HertelFernandez et al. 2019), which would preclude the use of list experiments for a small (generally $<500$ ) population like members of a Parliament or Congress (though not necessarily their staff). A real-world experiment designed to avoid social desirability bias or response bias is necessary to assess the responsiveness of legislators to constituent communications.

Given the difficulty of directly linking constituent communications on climate change to political decisions, Twitter offers a useful alternative forum for conducting such an experiment. By asking legislators to post a specific tweet, we can detect a fingerprint of our intervention that is more definitive than statistical changes in vote counts. While tweets are less impactful than legislation, studies suggest that politicians can use Twitter to influence their followers on a range of meaningful indicators, including voting intentions (Colliander et al. 2017) and vaccine hesitancy (Hornsey et al. 2020). With the increased willingness of media outlets to embed Twitter posts from politicians in their stories (Bane 2019; Dumitrescu and Ross 2020), and the potential for political parties (Seethaler and Melischek 2019) and campaigns (Kreiss 2014) to drive media cycles from Twitter, these posts should not be viewed as purely performative.

In this paper, we present the findings of an innovative field experiment testing the efficacy of online political participation. We partner with a non-partisan organization to run a realworld campaign where constituents asked their MPs to tweet about climate change. We then monitor the MPs' Twitter accounts to evaluate the effectiveness of the communication campaign, thereby measuring the responsiveness of MPs to outreach from their constituents on the high-salience issue of climate change.

First, we analyze the effectiveness of communicating using different frames on pro-climate tweeting. There is some evidence that framing climate communications in terms of their public health effects can lead to greater support for climate change mitigation (Kotcher et al., 2018; Maibach et al., 2010; Myers et al., 2012). Since framing might influence the decision to participate, we included a public health frame and a more typical environmental frame as a control. Then we look at the effect of email communication in general on changes in the rate of pro-climate tweeting compared to before the experiment took place.

We follow this experiment with interviews of political staff in MP offices to solidify our understanding of the efficacy of these campaigns, staffer management of constituent correspondence, and MP Twitter behavior. This serves the double purpose of exploring ways to encourage political elites to send stronger cues on climate change and of better understanding how climate activists can best engage with their elected representatives. 


\section{Methods}

\subsection{Study design}

To run the experiment, we partnered with Evidence for Democracy, a non-partisan, non-forprofit organization that promotes the use of evidence-based decision-making in Canadian government. Evidence for Democracy was founded by co-organizers of the "Death of Evidence" protests of 2012, initiated in response to research funding cuts and the closure of research stations (Chartrand 2012). Both the current staff and board of directors are largely composed of researchers and academics. Membership is concentrated in Ontario, British Columbia, and Quebec with a large segment of supporters consisting of academics, public servants, government researchers, and retired scientists. At the time of the campaign, approximately 6580 individuals followed Evidence for Democracy on Facebook, 5600 on Twitter, and 250 on Instagram. In addition to running educational and research programs, Evidence for Democracy raises awareness of scientific and policy-based issues in Canada and encourages members of the public to engage directly with policymakers.

Members of Evidence for Democracy were contacted by the organization using the organization listserv and an additional post made on Evidence for Democracy's Facebook page to recruit participation for the campaign. The initial email was sent to 15,556 members on May 4, 2019, with a follow-up reminder sent 5 days later to 15,335 recipients. Participating members were notified that the campaign was part of a study being conducted with researchers at the University of British Columbia. We assisted Evidence for Democracy in designing the text of a campaign email that asked Canadian MPs to post messages on their official Twitter accounts encouraging action on climate change. We then designed two different suggested tweets that MPs could post so as to reduce the cost of participation. One tweet represented a public health framing and the other an environmental framing. This also allowed us to extend the research on framing by testing on an important new population: elected officials. Both the campaign email and the tweets were available in English and French, Canada's two official languages (see Online Resource 1 for full text of the emails).

Public Health Tweet: Science tells us that climate change poses a significant public health threat, from increased asthma and heat stroke to the spread of disease due to extreme weather. Thanks to all the youth who voiced their concern \#Fridays4Future \#MarchforScience

Environmental Tweet: Science tells us that climate change stands to dramatically alter Canada's ecosystems, putting our cherished landscapes and iconic wildlife species at risk. Thanks to all the youth who voiced their concern \#Fridays4Future \#MarchforScience

The campaign was timed to coincide with the March for Climate rallies which were happening around Canada in early May of 2019. Prior to the experiment, we used block randomization according to political party to assign each Member of Parliament to one of two conditions. Randomization was conducted with the $\mathrm{R}$ package randomizr (Coppock 2019). All MPs received the same email, but half were given the public health tweet as an example of a tweet they might wish to send out, and half were given the environmental tweet. When members of Evidence for Democracy followed a link to participate, they entered their postal code and were automatically given the version of the campaign email containing the tweet that was assigned to their Member of Parliament. In this way a Member of Parliament only received emails 
containing the example of the public health tweet or the example of the environmental tweet, but not both.

\subsection{Data collection and analysis}

When the campaign concluded, we scraped tweets using the rtweet package from R (Kearney 2019), starting 7 days before the start of the campaign to act as a control and 10 days after the first day of the campaign to test the campaign's efficacy. Two MPs did not have twitter accounts at the time of the campaign, and because the campaign was conducted just prior to some byelections, three seats were not filled. In total we scraped 18,776 tweets from 333 MPs.

While collecting results, it became clear that there was insufficient Twitter participation from MPs to decisively evaluate which frame was more effective in persuading an MP to adopt and tweet out the suggested text. We therefore focused our analysis on whether receiving emails from constituents was a predictor of increased pro-climate tweets. We first evaluated the efficacy of the campaign emails by searching for the exact wording suggested in the example tweets included in the campaign emails. It is possible however that an MP would still be motivated by receiving an email to tweet about climate change but to choose their own distinct wording (this is especially true given that MPs prefer to maintain a consistent social media narrative). We filtered the 18,776 tweets by using a series of English and French keywords which included "global warm*," "climat*," "ghg," "greenhouse gas*," "effet de serre," "fossil," "carbon," "emit," "emett," "emis*," and "pipeline," thereby creating a subset of the data with 1723 relevant tweets ("pipeline" was included as the proposed expansion of the Trans-Mountain pipeline has become emblematic of the larger political conflict surrounding the carbon-intensive oil and gas industry). Two raters then went through the reduced set of tweets and coded them as either "pro-climate," "anti-climate," or "neutral." Full instructions for coding are available in Online Resource 2. Once all relevant tweets were coded, the two raters identified codes that were not agreed upon and discussed the coding until a consensus was achieved. The initial agreement was satisfactory $(\kappa=0.848)$.

To test for a relationship between message framing (or number of campaign emails) and Twitter activity, we ran a zero-inflated negative binomial regression with number of proclimate tweets in the experimental period as the outcome variable. Zero-inflated negative binomial models are appropriate for fitting overdispersed count data with excess zeroes (Hua et al. 2014). In our sample, these zero values can be expected from two sources: structural zeros from legislators who never post pro-climate tweets for ideological reasons and sampling zeros from legislators who may occasionally post pro-climate messages but happen to not do so during the course of the experiment. We controlled for confounding variables including the likelihood of being re-elected on the rationale that politicians are more responsive to constituents when they are likely to face a competitive election in the near future (McAlexander and Urpelainen 2020). To estimate likelihood of re-election, we used seat projections for each electoral district taken from 338canada.com on September 22, 1 month before the election, which categorized the lean of each district on a seven-point scale. Some MPs were randomized to a certain treatment (e.g., public health frame) but did not receive that treatment because no constituents in their riding sent them an email. To include these missing values or "noncompliers" and preserve the original balance from randomization, we used intention to treat (ITT) analysis (Gupta 2011). Therefore, in our analysis, every subject who was randomized is included according to their randomization assignment. Zero-inflated models were run in the pscl package in R (Zeileis et al., 2008). 


\subsection{Interviews}

To triangulate the findings from our Twitter experiment, we conducted semi-structured interviews with staffers in the MP offices. We reached out to every MP by email, debriefing them on the experiment, and asking if a member of their office would be willing to answer interview questions. Through the interviews, we sought to answer four research questions:

1) Are MP offices more responsive to larger volumes of communication from constituents?

2) Are MP offices more responsive to certain forms of communication (e.g., personalized emails versus campaign emails)?

3) How do MP offices manage social media accounts?

4) Do MP offices receive a higher volume of constituent communication on climate change than on other issues?

Because political staffers act as gatekeepers, determining which messages are shown to an MP as well as often managing an MP's social media accounts, we judged it more useful to speak with staffers than with MPs. This increased the likelihood of conducting more interviews, while offering the possibility of contributing to a sparse literature on the role of legislative aides as actors in the political process (Hertel-Fernandez et al. 2019).

To staffers who responded, we provided letters of consent (see Online Resource 3) and in order to save time for ostensibly busy staffers obtained consent orally. We contacted those who did not respond initially up to two additional times with reminder messages. The interviews lasted 10 to $15 \mathrm{~min}$. We transcribed interviews and then conducted thematic analysis according to a matrix-based method to identify emerging trends (Bryman 2008). Interviewees agreed to participate on conditions of anonymity, so some identifying details have been removed from the text. We received approval for all methods from the University of British Columbia's Behavioural Research Ethics Board.

\section{Results}

\subsection{Experimental findings}

We collected a total of 18,776 tweets for analysis. Of these, 1723 were flagged as potentially relevant to climate change based on our keyword search. We then coded each of those 1723 tweets as "pro-climate" (in favor of greater awareness or action on climate change) or "anticlimate" (dismissive of the existence, seriousness, or need for action on climate change). In total 1327 tweets were coded as pro-climate with substantial differences in the fraction of proclimate tweets by MPs in the various parties (Fig. 1). Twenty-six tweets were coded as anticlimate. Sixteen of the 26 anti-climate tweets were from MP Maxime Bernier, of the People's Party of Canada, while the remaining 10 were posted by six MPs from the Conservative Party of Canada.

During the email campaign, a total of 392 campaign emails were sent to Members of Parliament (see Table 1 for breakdown including randomization outcomes). Note that this excludes emails from constituents residing in the three ridings which were waiting on the results of a byelection. Even still, other campaigns run by Evidence for Democracy have resulted in greater rates of participation. Emails sent to MPs were not evenly distributed 


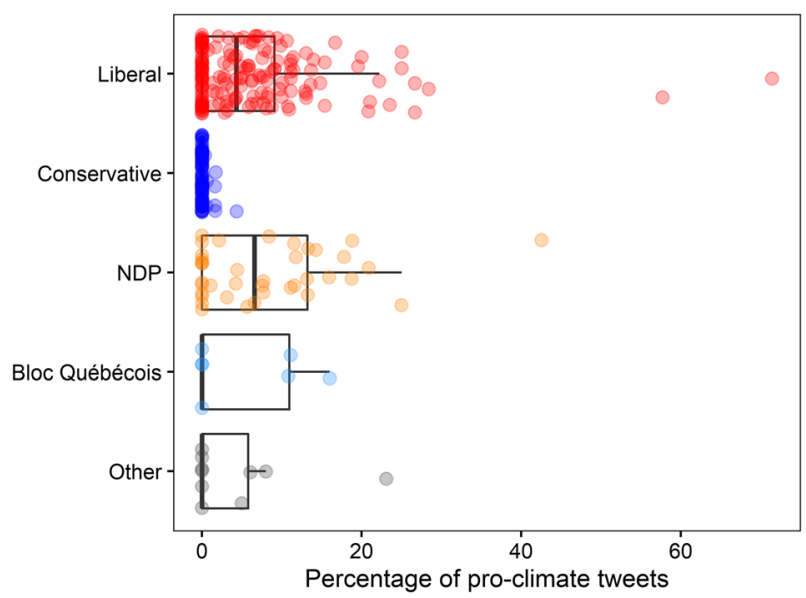

Fig. 1 Boxplot showing the percentage of all of an MP's tweets which were coded as "pro-climate" for each Canadian Member of Parliament, grouped by major political party

(Fig. 2). One hundred eighty-one MPs received no emails, while one MP received 28. Of these, only one MP, a Liberal Party member who received four emails from constituents, tweeted out the actual suggested text provided in the campaign emails.

Although only one MP tweeted out the exact text suggested in the campaign email, it is possible that MPs receiving the constituent email would still feel pressured to write a different post about climate change which fit their office's narrative more closely (see the Interview Findings). We first evaluate whether MPs in the health communication frame increased their pro-climate tweeting more than those in the pro-environmental frame. There was a downward trend in the rate of pro-climate tweeting from the pre-experiment to post-experiment periods, but there was no difference between MPs who received an environmental frame and those who received a public health frame (Fig. 3).

Because we could not control which members of Evidence for Democracy sent emails to their representatives, there was an uneven number of messages to MPs from the two groups: 221 emails with the environmental framing went out to 79 MPs, while 171 emails with the public health framing went out to 75 MPs. Still, this did not amount to a statistically significant difference in the mean number of emails received by MPs in the two groups $(t=1.11,95 \% \mathrm{CI}$ $[-0.227,0.810], p=.27)$. We ran a zero-inflated negative binomial model to control for the

Table 1 Composition of Canadian Members of Parliament at the time of the experiment

\begin{tabular}{|c|c|c|c|c|c|c|c|}
\hline Party & $\begin{array}{l}\text { Members } \\
\text { of } \\
\text { Parliament }\end{array}$ & Female & Male & $\begin{array}{l}\text { Tweets during } \\
\text { analysis period }\end{array}$ & $\begin{array}{l}\text { MPs receiving } \\
\text { environment } \\
\text { frame }\end{array}$ & $\begin{array}{l}\text { MPs receiving } \\
\text { public-health } \\
\text { frame }\end{array}$ & $\begin{array}{l}\text { Total } \\
\text { emails } \\
\text { received }\end{array}$ \\
\hline Liberal & 177 & 50 & 127 & 10,308 & 46 & 43 & 267 \\
\hline Conservative & 97 & 18 & 79 & 4160 & 17 & 22 & 66 \\
\hline NDP & 41 & 17 & 24 & 2218 & 12 & 7 & 48 \\
\hline $\begin{array}{l}\text { Bloc } \\
\text { Québé- } \\
\text { cois }\end{array}$ & 10 & 2 & 8 & 145 & 2 & 1 & 4 \\
\hline Other & 10 & 4 & 6 & 1945 & 2 & 2 & 7 \\
\hline Total & 335 & 91 & 244 & 18,776 & 79 & 75 & 392 \\
\hline
\end{tabular}




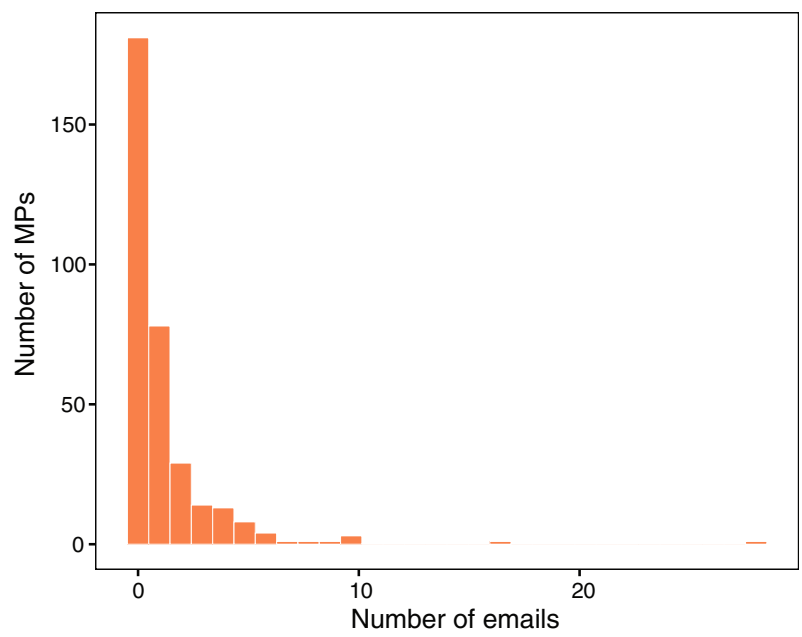

Fig. 2 Histogram showing the distribution of number of emails received by Members of Parliament during the campaign

number of opportunities an MP had to make a pro-climate tweet (the number of tweets in the experimental period), the number of emails received, and other potential confounders. We failed to find evidence for a difference in the number of pro-climate tweets between the two messaging groups (Table 2).

The regression model also shows whether receiving constituent contact, regardless of message frame, increased pro-climate tweeting generally. In a successful campaign, we might expect that MPs who received more emails would be more likely to increase the number of pro-climate tweets than those who did not. But, in the zero-inflated negative binomial regression, the number of emails received by an MP was only a marginally significant predictor of the number of pro-climate tweets posted in the experimental period. The effect of a single additional email was estimated at 1.055 (=exp.(0.054), $p=.069)$. If this is a true

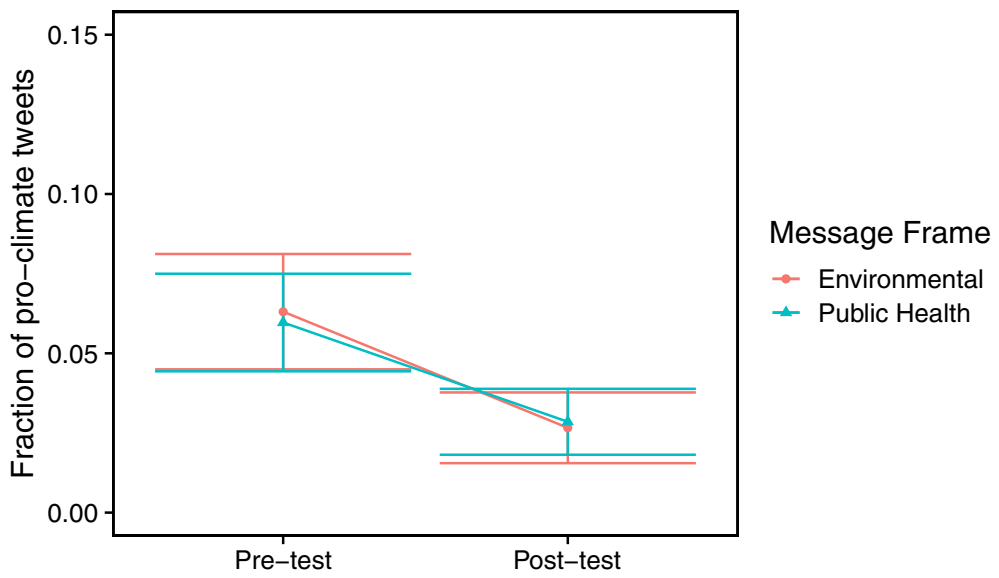

Fig. 3 Error bars show the $95 \%$ confidence interval of the mean fraction of tweets which were coded as proclimate in the pre-experiment and post-experiment periods 
Table 2 Results from the zero-inflated negative binomial ITT model predicting pro-climate tweeting

\begin{tabular}{llcl}
\hline & Coefficient & Standard error & $p$ value \\
\hline & \multicolumn{2}{c}{ Counts portion of the model } & \\
Email frame (public health) & 0.028 & 0.206 & .890 \\
Pre-trial pro-climate tweeting & 2.277 & 0.954 & .017 \\
Number of emails & 0.054 & 0.030 & .069 \\
Party & & & $<0.001$ \\
Conservative & -4.514 & 0.800 & .002 \\
Liberal & -1.917 & 0.618 & .135 \\
NDP & -0.979 & 0.655 & .013 \\
Other & -1.905 & 0.767 & .171 \\
District competitiveness & -0.095 & 0.070 & .064 \\
Constant & -1.288 & 0.695 & .650 \\
& Logistic portion of the model & .112 \\
Pre-trial pro-climate tweeting & -22.550 & 49.651 & .068 \\
Tweets in experimental period & -0.190 & 0.120 & 1.336 \\
Constant & 2.441 & & \\
\hline
\end{tabular}

Note: $N=335$, Log Likelihood $=-304.047$; pre-trial pro-climate tweeting is fraction of pre-trial tweets coded as pro-climate; district competitiveness is from 0 to 6 where 6 is a safe district

effect, it would mean that, other variables held constant, an MP receiving an additional email would be expected to post 5.5\% more pro-climate tweets (see Online Resource 4 for details).

\subsection{Interview findings}

We conducted interviews with 12 MP staffers from 11 MP offices. Provinces represented included British Columbia (5 MP offices), Ontario (3), Saskatchewan (1), Alberta (1), and Manitoba (1). Staffers worked for MP offices from the Liberal Party of Canada (8), the New Democratic Party (2), the Conservative Party of Canada (1), and one office not belonging to the top four political parties. We specifically sought out staffers who were responsible for managing constituent communication and or managing the MP's social media accounts.

\subsection{Volume of communication}

We began the interview by asking staffers if there was a threshold number of communications required from constituents to raise an issue with the MP. There was no consensus on how MP offices act in this regard. Only two staffers described an actual volume of constituent communications that would prompt them to involve their MP, and even then, the responses were more qualitative than quantitative:

Definitely if we receive more than two calls in a day about a topic, we would be letting him know ... that's pretty unusual for us to receive more than two calls in a day about a specific topic

...there isn't actually a codified threshold but we typically get little tricklings in of like five correspondence ... As soon as we start to see we'll get thirty now on this one, then we go something is up ... if you get six thousand - okay there's a bot.

These responses suggest that a high volume of emails is not always necessary to at least reach the MP and may be detrimental if the campaign suspects astroturfing or other types of foul play such as automated emails (bots). 
Two staffers said the process was issue dependent, with more weight given to issues that are relevant to the riding association or the MP's office. Three staffers said they observe trends in communication and use those to inform the MP of which issues are becoming more salient for their constituents, "usually there's an issue that becomes popular and we get a lot of e-mails on that specifically and then that's the one we send over to him." Two staffers noted that the type of communication helped them determine if the message was worth sending to their MP, with less weight given to campaign emails. One interviewee said, "if an e-mail is a campaign, so if it's something we're getting repeatedly, our support staff at the Liberal research bureau will create a party response to the issue. So it doesn't necessarily need to be brought up to [name of MP], because there's already party lines provided."

This raises the complication that a letter can be effective either because it is actually seen by an MP and therefore has the chance to persuade them or because it is added to a tally that informs the decisions of the MP or the party apparatus: "when it comes to e-mails we do keep track and ... gauge whether or not they're pro or they're anti for an issue." Another staffer noted that they "keep tallies on who calls in ... who e-mails in about what, and all the offices do that, and [staff at the political party] keep track of it." In this way, it is possible for constituent contact to bypass individual MPs and directly inform policy changes at the party level.

Without prompting, five staffers also noted that they prioritized communications from constituents. This took the form of responding to constituent communications first, only responding to constituents, or preferentially alerting their MP of communications that came from within the district. One staffer noted that while constituent communications are prioritized, some additional weight is given to messages that at least come from near the district since there were few other representatives from the same party in that region.

\subsection{Form of communication}

Ten of the twelve staffers were able to comment on which type of communication was given more weight in decision-making. All staffers agreed that campaign emails (or form emails) were given either equal or lesser treatment compared to personalized emails, hand-written letters, or phone calls. Five staffers described a hierarchy with campaign emails on the bottom. For instance, one mentioned that when they received personalized messages, they tried to set up a phone call with the constituent, while another described how hand-written letters receive personal responses from the MP. Both of these staffers observed that campaign emails only receive generic responses in their office.

Other staffers were very explicit in describing a hierarchy, saying for instance that "Hand-written letters are certainly more impactful than emails and form emails," while another noted that if a message comes through the MP's website, it "definitely weigh(s) more heavily than a blanket campaign letter." One MP went so far as to identify four levels of impact with a personalized hand-written letter being the most impactful, followed by a form letter that is mailed, then a personalized email, and finally campaign emails. They went on to say "a hundred e-mails about one issue ... like each person has written their own e-mail, that will make us think about it. But a hundred [hand-written] letters would really give you pause to think about what's going on, and to try to figure out how you respond."

Still, this was not a unanimous belief: two staffers maintained that all communications were treated equally, while a third claimed that campaign emails had lower weight for the MPs but equal weight when sending numbers to the political party apparatus. Two other staffers did not 
rank campaign emails as being less impactful but believed that the process of responding to a hand-written letter endowed it with more meaning,

When a letter comes in, someone has to physically open it and read it. An e-mail comes in and you get blasted with it... don't want to say we don't read them, we read all those, maybe really quickly ... and then go to the next one.

\subsection{Managing social media}

In order to understand the process whereby a staffer would evaluate and potentially acquiesce to a constituent request for a social media post, we asked interviewees to describe how their office handles the MP's Twitter communication. Staffer responses indicated substantial differences between offices. Four offices described their MP as maintaining control over their own Twitter account. In two of these cases, the staffer indicated that the MP personally reviewed every item of constituent correspondence, making for a straight path between a constituent request for a Twitter post, like in this study, and the fulfillment of that request. In four cases, the MP co-managed the Twitter account with the same staff member who managed correspondence. In three offices, the staffers who received constituent communication were not necessarily the same as those who helped to manage the MP's social media account. In those offices, there would need to be coordination in order for a social media request from constituents to be carried out.

Two interviewees recalled receiving the constituent request from the experiment. One described maintaining a general policy of not tweeting the suggestions of constituents due to the abundance of requests, many of which were viewed as irrelevant: “...we don't really tweet things on suggestion of constituents, as a general policy. Because, A) you get too many requests. B) A lot of requests are inappropriate or irrelevant. And C) It's outside the tone of [M.P.'s name] general social media presence." The other staffer noted the difficulties of matching the suggested text with their MP's desired narrative as well as the problematic timing of the particular request: "I do remember that ... by the time it made its way to me it was sort of a late Thursday night and we had a jam-packed Friday schedule which is why we didn't move forward with it. And if I recall correctly as well, the message that was being asked ... wasn't an easy fit with his typical narrative on the issue."

\subsection{Is communication on climate change saturated?}

Interviewees were asked, "Compared to other issues, do you feel like you receive a lot of correspondence from constituents about climate change?" Responses to this question were mixed. Three interviewees said that they received a below average amount of communication on this issue, for instance, "We don't have a whole lot of personal people writing in their personal thoughts of climate change. We get a lot of form letters that somebody's found a website that automatically sends an e-mail to their MP." Another staffer perceived a gap between how much climate communication the staffer expected to receive and what is actually received: "It's unfortunate, it surprises me how little activism there is on climate change, like [MP name] is the [name of position], and still we get very little letters and things here about that." Another interviewee described the volume of communication on climate change as average but added that "whenever my boss is out in the community it's one of the first things that comes up. I don't feel it correlates to the amount of letters and e-mails we receive in 
regards to climate change. I would have expected it to be more, so I would say we get an average amount, when I feel we should be getting a higher amount."

Seven offices believed the amount of communication on climate change was above average. Several of these staffers noted that the MP's portfolio or the composition of their ridings might explain this focus. One staffer mentioned that "Climate change and water management is a very big issue where [they are] from," while another said that "Climate change is always a big topic and, I think especially going into flood and forest fire season in [name of province] , I think is something that's gonna ramp up even further."

Some interviewees identified the difficulty of drawing boundaries around the issue, as climate change can exacerbate natural resource problems or be taken into consideration when approving new fossil fuel infrastructure like pipelines. One interviewee noted that because their constituency is in Alberta, which has a heavy oil and gas industry presence, they receive correspondence with "a bit more balance on the environment issues," indicating that not all communication on the issue of climate change consists of a pro-climate message. Two interviewees also observed that climate can be more or less represented in constituent communication depending on current events and media focus.

\section{Discussion}

Mass communication campaign emails are a primary tool of contemporary climate action, even though researchers believe that their efficacy may be declining (Cluverius 2017). While some climate organizations may track the success of interventions like campaign emails or phone calls, their data is not generally available to the public. Everyday citizens would therefore benefit from understanding which political actions merit their effort. If, for instance, campaign emails are largely discarded by political staffers without even being read, then climate activists should not waste resources on those interventions. But this study points to a middle-ground: The statistical results and interviews suggest that it is possible for campaign emails to influence MPs' public support for climate action, but that it is not realistic to expect MPs to share exact language provided by constituents (due to party message discipline), and that the effect of campaign emails is marginal and likely lower than that of old-fashioned letters or in-person communication.

The empirical insights provided by this experiment add to a field that is largely speculative. Only one MP fulfilled the constituent request to post a pro-climate tweet, and we found no statistical difference in the frequency of pro-climate tweets between those who received an environmental versus a public health frame. We also found only a marginal statistical difference in the frequency of pro-climate tweets of those who received messages compared to those who did not. ${ }^{1}$ This positive effect of the constituent communication may be unique to experimental design and the sample and would need to be confirmed by further research.

The overall lack of MP response to the constituent requests in the experiment remains notable given the low-cost, symbolic nature of the requested action: posting a pro-climate message on Twitter. Campaigns regularly seek for more substantial action from elected officials, like requesting a vote against party lines. The request in this study demands a much

\footnotetext{
${ }^{1}$ At the suggestion of a reviewer, a reasonable way to interpret the data is using a one-tailed $p$ value (given the clear directional hypothesis we stated earlier in the paper). When viewed this way, this means that each additional email translated into a $5.5 \%$ increase in pro-climate tweets.
} 
lower level of persuasion by the constituents. Some MPs manage both their own social media and review all constituent correspondence, while in some other cases, the staffers who manage MPs' Twitter accounts are often the same staffers who deal with messages from constituents. In such cases, the obstacles to participation are low since fulfilling the request does not even require communication between multiple actors. Furthermore, it is common for MPs to tweet more than ten times per day, so a single tweet on the topic of climate change would not necessitate a large shift in messaging strategy. An alternative interpretation is that a social media request may seem less important in the eyes of the MP offices than constituent requests to vote a certain way on legislation. The perceived stakes associated with the campaign request may matter in addition to how easily the request can be satisfied.

MPs from the Conservative Party may have also been hesitant to send a signal that is at odds with the messaging strategy of their party, but they are an exception. Their reticence does not explain why only one of the 115 MPs from other parties who received emails from their constituents was willing to post the suggested message on Twitter. Our use of an experiment instead of surveys to determine the responsiveness of elected officials avoids the response bias and social desirability bias that would weaken the findings of a similar investigation performed with surveys alone. This method of investigation does however necessitate certain tradeoffs. First, studies on political elites are understandably restricted to a small sample size (we analyzed 335 MPs for this experiment). Similarly, performing a realistic experiment required us to partner with an actual organization, in this case Evidence for Democracy. We chose a non-partisan organization with the intent of reducing the tendency for right-leaning MPs to dismiss the persuasive communication outright. But given the partisan divide on some sciencepolicy issues in Canada (Lachapelle et al. 2012), Evidence for Democracy and its membership may not be viewed by MPs as non-partisan (Liberals received over twice as many emails per MP as Conservatives). Evidence for Democracy also has a smaller membership than other organizations, and the fact that the campaign centered on social media posts instead of more galvanizing topics in Canadian politics resulted in only 392 emails going out to MPs. This is not necessarily a flaw since more communications are not necessarily more effective, but it does limit the generalizability of our results to smaller campaigns. Additionally, the campaign was timed to coincide with the Fridays for Future and the March for Science marches. Possibly due to this timing, MPs posted more pro-climate tweets per day in the control period, and by the time campaign communications had been relayed to them, they may have been disinclined to tweet on the subject again. Finally, there may be potential confounders that our regression failed to take into account. As an example, members of Evidence for Democracy who sent emails may live in communities with higher concern for climate change and be served by representatives who would be more willing to tweet about climate change when prompted. We tried to control for this first by using Party and number of pro-climate tweets in the pre-experiment period as predictor variables, but other, unconsidered confounders may still be present.

While the use of a field experiment increases the study's external validity, the effort required to conduct a single experiment of this type means that we were only able to test a single intervention (with two types of messaging frames). Emails could have been designed to be more or less persuasive or be sent from email addresses that carry more or less weight with legislators and so forth. Rather than assuming that these particular campaign emails are widely representative, one could instead view the experiment as a confirmation of the interview findings: MP offices do read messages, but only a certain combination of volume, content, and timing will prompt offices to act on constituent requests. 


\subsection{Theories of representation}

The level of responsiveness shown by MPs in the experiment speaks to the models of representation favored by Canadian officials. MPs may think of their representative role as "promissory" (fulfilling election promises), "anticipatory" (attempting to please future voters), "gyroscopic" (acting as a trustee with internal motivations), or "surrogate" (representing nonconstituents) (Mansbridge 2003). Because climate legislation creates benefits that are spread across the globe and across generations, but concentrates costs, elected officials may struggle to act in promissory or anticipatory fashion while supporting ambitious climate legislation (Willis 2018). How Canadian MPs view their role as representatives can therefore be critical to how they legislate on climate change. In interviews, MP staffers described a focus on constituents at the expense of those not in their riding (which shows a tendency towards the anticipatory or promissory models). Experiments like this one can also shed light on the models of representation favored by legislators, with greater responsiveness to constituent requests indicating that legislators are aligning themselves with future voters.

\subsection{Implications of the study}

Integrated together, the experiment and interviews provide evidence about the general effectiveness of individual political actions. If campaign emails sent within 6 months of an election are unable to persuade MP offices to make a token statement on social media, then they are unlikely to achieve larger changes such as persuading an elected official voting against party lines. Such vote shifts also represent a rather ineffective way of influencing national politics: the Canadian political system is even less amenable to dissenting votes than other Westminster-style parliaments, and parties incentivize conformity by denying promotions and coveted committee positions to dissenters (Malloy 2003). The interviews suggest that the greater political impact of communication from constituents, whether via campaign emails or more individually persuasive hand-written letters, may be on party or governing strategy rather than a vote in the legislature. Though follow-up research is needed to understand if all parties operate in the same way, one interviewee described how every office in their party delivers tallies of constituent communication to the central party.

This influence is evident in internal party negotiations about climate and energy policy decisions. For example, in Canada, MPs of the governing party (ostensibly informed by the preferences of their constituents) meet with the Prime Minister in weekly sessions where they have the opportunity to influence the government's agenda (Malloy 2004). The debate within the Liberal cabinet over whether to approve the Teck Frontier oilsands project serves as a recent example, with members of cabinet taking sides largely based on the preferences of their constituents (Leblanc and Walsh 2020). This highlights some regional differences in the power of individual voters, where constituents represented by members of the governing party have greater influence over national decision-making. But, constituencies of other parties still command some leverage, especially in situations where the governing party retains only a plurality of seats in the legislature (as is the case for the current minority government in Canada). In such cases, the governing party tends to be especially sensitive to public opinion and criticisms leveled by the opposition parties (Bourgault 2011). Furthermore, there is evidence that representatives in party-centered systems may work to change the views of fellow party members when those views are in opposition with the preferences communicated by constituents (Öhberg and Naurin 2016). While persuading individual MPs or political 
parties through emails might not generate change that can be experimentally observed, there is evidence that such efforts are still worthwhile.

Regarding the hypothesis that public health messages can be more persuasive than environmental messages, we view the findings of this study as equivocal. Interviewees referred to the importance of message discipline, which suggests that Twitter may be a difficult forum to conduct an experiment on message framing in particular. That being said, a similar experiment using more personalized messages and run on a larger group of legislators may have elicited a detectable difference between messaging frames.

\subsection{Future research needs}

This research points to a variety of avenues for future research on the effectiveness of different political actions in addressing climate change. Results from the interviews suggest that campaign emails may be more effective at informing party decisions than decisions of individual MPs. It is possible that campaigns targeting a small number of swing votes on climate legislation would do better to use personalized emails, phone calls, and hand-written letters, whereas efforts to change the priorities of party leadership could still rely on generic campaign emails. More generally, there is a need to understand how different forms and volumes of communication about climate change are viewed by subnational elected officials and by officials in other governing systems. For instance, officials with a smaller number of constituents, like city councilors, may be considerably more responsive than national officials.

As political science makes greater use of field experiments, responsiveness can be measured by social media posts, whether an official sends a reply to constituent outreach (Butler et al. 2012), the quality of that reply (Richardson and John 2012), the willingness to meet with a constituent (Kalla and Porter 2019), and the willingness to co-sponsor new legislation or change a vote on tabled legislation. Additional experiments that match these dependent variables with different forms of persuasion (phone calls, petitions, and perhaps even protests) can provide insight into how citizens best engage with their representatives.

Our experiment tried to make use of secondary beliefs to encourage climate action first by elites and then by their followers, but campaigns could use other strategies that capitalize on secondary beliefs. For example, research might test a normative appeal about how many other people are contacting their elected officials as a way to increase the number of members that send emails to their legislators. In an experiment similar to ours, a message to legislators could include public opinion information to signal to legislators that their constituents would like them to act more on climate change.

Finally, there are multiple ways to incorporate advocacy group expertise into research. One approach is to engage in academic-practitioner collaborations that treat the practitioners as a full partner in experimental research from conceptualization to execution (Levine 2020, 2021). Our study represents an instance of this kind of collaboration. However, another useful model is to partner with advocacy groups to document and synthesize their existing expertise and use that to inform theory and future research (e.g., see Han et al. (2017) and Sherman et al. (2020)). Both forms of research are valuable to increasing the societal impact of research on climate change communication, and organizations like Climate Access, Climate Outreach, research4impact, and The Climate Advocacy Lab could help to facilitate such collaborations. 


\subsection{Recommendations}

Interviews with campaign staffers showed that elected officials are not so saturated with communication on climate change that additional outreach from constituents would be ignored. And if there is still value for campaigners and individuals in reaching out to their representatives, then it is worthwhile to know the most effective ways of doing so.

While mass campaign emails remain more effective than no action at all, organizations seeking to maximize their impact on the political decision-making process with respect to climate change should consider diversifying methods of contact. Phone banks, letter-writing parties, and personalized emails all have the potential to be more persuasive on a per-communication basis than campaign emails. Campaigners often seek to intervene in political decisions that arise suddenly, in which case online communications have an obvious advantage over hand-written letters or postcard campaigns, but phone calls would still be timely and possibly more effective. Personalized emails or letters also require more effort and may result in a lower volume of communication, but there could be diminishing returns to high volumes of repetitive communication if elected officials and their staff fail to see these as sincere efforts at outreach. Alternatively, recruiting activists to make more phone calls may generate its own set of obstacles, such as unwillingness on the part of socially anxious individuals to participate (Reid and Reid 2007). In the short term, if large, organized protests are curtailed by increased social distancing (as a legacy of the COVID-19 pandemic), it will be especially important for members of the climate movement to understand how to better persuade elected officials using other means.

Climate campaigners have a unique opportunity during climate strikes and other protests to recruit mobilized individuals to contact their representatives. A survey of protestors attending the Fridays for Future rallies in 13 cities found that of the largest age group, teenagers, only $10 \%$ had ever contacted a government official (Wahlström et al. 2019). Each gathering features a large captive audience, who, though engaged in protesting, could be maximizing their impact by also writing short, hand-written letters to their MPs or leaving a phone message at their MPs office. Based on our experimental results and the interviews conducted with MP staffers, these interventions are expected to be more effective than campaign emails. Organizing group communication at a protest would ensure that multiple interventions not only occur at the same time but also coincide with increased media attention. This would signal the kind of trend that MP staffers described as sufficient justification to notify their Member of Parliament and is consistent with expert belief that the attention of political actors is influenced by recent events (Jones and Baumgartner 2005). In addition to generating necessary pressure on politicians to act on climate change, organizing group communications of this sort would also better educate members of the public on how to communicate with their representatives, allowing for lasting civic engagement.

Supplementary Information The online version contains supplementary material available at https://doi.org/ 10.1007/s10584-021-03215-9.

Code availability Code is available upon request.

Author contribution SW: Conceptualization, methodology, investigation, and writing - reviewing and editing. JK: Methodology and writing — reviewing and editing. SD: Supervision and writing - reviewing and editing.

Data availability Data is available upon request subject to our ethics agreement. 


\section{Declarations}

Ethics approval Ethics approval was granted by the UBC Behavioural Research Ethics Board under UBC ethics certificate number H19-00933.

Consent to participate Consent to participate was obtained from all participants (see the supplement for full forms).

Conflict of interest The authors declare no competing interests.

\section{References}

Bane KC (2019) Tweeting the agenda: how print and alternative web-only news organizations use Twitter as a source. Journal Pract 13:191-205

Bourgault J (2011) Minority government and senior government officials: the case of the Canadian federal government. Commonw Compa Politics 49:510-527

Bricker D (2019) Four weeks in, climate change is fastest-moving $(29 \%,+4)$, but health care (35\%) still top issue to make a difference at the ballot box. Ipsos

Broockman DE, Skovron C (2018) Bias in perceptions of public opinion among political elites. Am Polit Sci Rev 112:542-563

Brulle RJ, Carmichael J, Jenkins JC (2012) Shifting public opinion on climate change: an empirical assessment of factors influencing concern over climate change in the US, 2002-2010. Clim Chang 114:169-188

Bryman A (2008) Social research methods. Oxford University Press, Oxford, United Kingdom

Butler DM, Broockman DE (2011) Do politicians racially discriminate against constituents? A field experiment on state legislators. Am J Polit Sci 55:463-477

Butler DM, Karpowitz CF, Pope JC (2012) A field experiment on legislators' home styles: service versus policy. J Polit 74:474-486

Carmichael JT, Brulle RJ (2017) Elite cues, media coverage, and public concern: an integrated path analysis of public opinion on climate change, 2001-2013. Env Polit 26:232-252

Chartrand F (2012) Scientists take aim at Harper cuts with 'death of evidence' protest on Parliament Hill. The Globe and Mail

Cluverius J (2017) How the flattened costs of grassroots lobbying affect legislator responsiveness. Polit Res Q 70:279-290

Colliander J, Marder B, Lid Falkman L, Madestam J, Modig E, Sagfossen S (2017) The social media balancing act: testing the use of a balanced self-presentation strategy for politicians using twitter. Comput Human Behav 74:277-285

Coppock A (2019) Package randomizr: easy-to-use tools for common forms of random assignment and sampling

Docherty DC (2001) To run or not to run? A survey of former Members of the Parliament of Canada. Canadian parliamentary review $24: 16$

Dumitrescu D, Ross AR (2020) Embedding, quoting, or paraphrasing? Investigating the effects of political leaders' tweets in online news articles: the case of Donald Trump. New Media \& Society: 1461444820920881

Environment and Climate Change Canada (2020) Canadian environmental sustainability indicators. Gatineau, Quebec

Gardner GT, Stern PC (2008) The short list: the most effective actions US households can take to curb climate change. Environ Sci Policy Sustain Dev 50:12-25

Geiger N, Swim JK (2016) Climate of silence: pluralistic ignorance as a barrier to climate change discussion. J Environ Psychol 47:79-90

Glynn AN (2013) What can we learn with statistical truth serum? Design and analysis of the list experiment. Public Opin Q 77:159-172

Gupta SK (2011) Intention-to-treat concept: a review. Perspect Clin Res 2:109

Han H, Barnett-Loro C (2018) To support a stronger climate movement, focus research on building collective power. Front Commun 3:55

Han H, Sparks AC, Towery ND (2017) Opening up the black box: citizen group strategies for engaging grassroots activism in the twenty-first century. Interest Groups \& Advocacy 6:22-43

Hertel-Fernandez A, Mildenberger M, Stokes LC (2019) Legislative staff and representation in congress. Am Polit Sci Rev 113:1-18 
Hooghe M, Marien S (2012) How to reach Members of Parliament? Citizens and Members of Parliament on the effectiveness of political participation repertoires. Parliamentary Affairs:gss057

Hornsey MJ, Finlayson M, Chatwood G, Begeny CT (2020) Donald Trump and vaccination: the effect of political identity, conspiracist ideation and presidential tweets on vaccine hesitancy. J Exp Soc Psychol 88: 103947

Hua H, Wan T, Wenjuan W, Paul C-C (2014) Structural zeroes and zero-inflated models. Shanghai Arch Psychiatry 26:236

Jones BD, Baumgartner FR (2005) The politics of attention: how government prioritizes problems. University of Chicago Press

Kalla J, Porter E (2019) Correcting bias in perceptions of public opinion among American elected officials: results from two field experiments. British Journal of Political Science 1-9

Kearney M (2019) rtweet: collecting and analyzing twitter data. Journal of Open Source Software 4:1829

Kreiss D (2014) Seizing the moment: the presidential campaigns' use of Twitter during the 2012 electoral cycle. New Media Soc 18:1473-1490

Kotcher J, Maibach E, Montoro M and Hassol SJ (2018) How Americans Respond to Information About Global Warming's Health Impacts: Evidence From a National Survey Experiment. GeoHealth 2(9):262-275. https:// doi.org/10.1029/2018GH000154

Lachapelle E, Borick CP, Rabe B (2012) Public attitudes toward climate science and climate policy in federal systems: Canada and the United States Compared 1. Rev Policy Res 29:334-357

Lacroix K (2018) Comparing the relative mitigation potential of individual pro-environmental behaviors. J Clean Prod

Leblanc D, Walsh M (2020) Teck's Frontier oil sands project faced push back from Liberal cabinet ministers: though Teck withdrew its application for the Frontier project, the internal debate highlighted divisions among Liberals who were trying to balance the party's environmental agenda. The globe and mail (online)

Levine AS (2020) Research impact through matchmaking (RITM): why and how to connect researchers and practitioners. PS: Political Science \& Politics 53:265-269

Levine AS (2021) How to form organizational partnerships to run experiments. Adv Exp Polit Sci 199

Maibach EW, Nisbet M, Baldwin P, Akerlof K, Diao G (2010) Reframing climate change as a public health issue: an exploratory study of public reactions. BMC Public Health 10(1). https://doi.org/10.1186/14712458-10-299

Malloy J (2003) High discipline, low cohesion? The uncertain patterns of Canadian parliamentary party groups. J Legis Stud 9:116-129

Malloy J (2004) The executive and parliament in Canada. J Legis Stud 10:206-217

Mansbridge J (2003) Rethinking representation. Am Polit Sci Rev:515-528

McAlexander RJ, Urpelainen J (2020) Elections and policy responsiveness: evidence from environmental voting in the US congress. Rev Policy Res 37:39-63

McDonald S (2019) Constituent correspondence in the U.S. congress: a survey of staff perspectives. Democracy Fund

McNutt J, Boland K (2007) Astroturf, technology and the future of community mobilization: implications for nonprofit theory. J Soc Soc Welfare 34:165

Merkley E, Stecula DA (2020) Party cues in the news: democratic elites, republican backlash, and the dynamics of climate skepticism. Br J Polit Sci:1-18

Mildenberger M, Tingley D (2017a) Beliefs about climate beliefs: the importance of second-order opinions for climate politics. Br J Polit Sci 49:1279-1307

Mildenberger M, Tingley D (2017b) Beliefs about climate beliefs: the importance of second-order opinions for climate politics. Br J Polit Sci:1-29

Mildenberger M, Howe P, Lachapelle E, Stokes L, Marlon J, Gravelle T (2016) The distribution of climate change public opinion in Canada. PLoS One 11

Myers TA, Nisbet MC, Maibach EW, Leiserowitz AA (2012) A public health frame arouses hopeful emotions about climate change. Climatic Change 113(3-4):1105-1112. https://doi.org/10.1007/s10584-012-0513-6

Nederhof AJ (1985) Methods of coping with social desirability bias: a review. Eur J Soc Psychol 15:263-280

Nokken TP (2000) Dynamics of congressional loyalty: party defection and roll-call behavior, 1947-97. Legis Stud Q:417-444

Ockwell D, Whitmarsh L, O'Neill S (2009) Reorienting climate change communication for effective mitigation: forcing people to be green or fostering grass-roots engagement? Sci Commun 30:305-327

Öhberg P, Naurin E (2016) Party-constrained policy responsiveness: a survey experiment on politicians' response to citizen-initiated contacts. Br J Polit Sci 46:785-797

Reid DJ, Reid FJ (2007) Text or talk? Social anxiety, loneliness, and divergent preferences for cell phone use. CyberPsychol Behav 10:424-435 
Richardson L, John P (2012) Who listens to the grass roots? A field experiment on informational lobbying in the UK. Br J Polit Int Relat 14:595-612

Rinscheid A, Pianta S, Weber EU (2020) What shapes public support for climate change mitigation policies? The role of descriptive social norms and elite cues. Behav Public Policy:1-25

Rogelj J, Den Elzen M, Höhne N, Fransen T, Fekete H, Winkler H, Schaeffer R, Sha F, Riahi K, Meinshausen M (2016) Paris Agreement climate proposals need a boost to keep warming well below 2 C. Nature 534:631639

Seethaler J, Melischek G (2019) Twitter as a tool for agenda building in election campaigns? The case of Austria. Journalism 20:1087-1107

Sherman DK, Shteyn MF, Han H, Boven LV (2020) The exchange between citizens and elected officials: a social psychological framework for citizen climate activists. Behav Public Policy:1-30

Taddicken M, Kohout S, Hoppe I (2019) How aware are other nations of climate change? Analyzing Germans' second-order climate change beliefs about Chinese, US American and German people. Environ Commun 13:1024-1040

Wahlström M, Sommer M, Kocyba P, de Vydt M, De Moor J, Davies S, Wouters R, Wennerhag M, van Stekelenburg J, Uba K (2019) Protest for a future: composition, mobilization and motives of the participants in Fridays For Future climate protests on 15 March, 2019 in 13 European cities

Willis R (2018) Constructing a 'representative claim' for action on climate change: evidence from interviews with politicians. Polit Stud 66:940-958

Wynes S, Nicholas K (2017) The climate mitigation gap: education and government recommendations miss the most effective individual actions. Environ Res Lett:12

Wynes S, Zhao J, Donner SD (2020) How well do people understand the climate impact of individual actions? Clim. Change 162:1521-1534

Wynes S, Motta M, Donner SD (2021) Understanding the climate responsibility associated with elections. One Earth 4:363-371

Zeileis A, Kleiber C, Jackman S (2008) Regression models for count data in R Journal of statistical software 27(8):1-25. http://dx.doi.org/10.18637/jss.v027.i08

Publisher's note Springer Nature remains neutral with regard to jurisdictional claims in published maps and institutional affiliations. 